\title{
CLAUDIUS AQUEDUCT IN ROME - KINEMATIC ANALYSES AND EMPIRICAL EXPERIENCES FOR THE DEFINITION OF STRUCTURAL RESTORATION INTERVENTIONS
}

\section{FABRIZIO DE CESARIS ${ }^{1}$}

${ }^{1}$ Sapienza, Università di Roma, Piazza Borghese 9, 00186 Rome, Italy

e-mail: fabrizio.decesaris@uniroma1.it, www.uniroma1.it

Keywords: Historical Structure, Masonry, Structural restoration, Consolidation, Empirical study, Reinforcement minimization.

\begin{abstract}
Present work summarizes a study on the stability of some parts of the Claudius Aqueduct in Rome (1st century AD). The project provides empirical applications linked to the definition of minimal interventions for the structural restoration of a section of the structure near Capannelle. Results of the kinematic analyzes conducted and of experiment with a physical model representing the structure of the upper hydraulic conduit (speco) are reported. Ultimately, hypothetical minimal interventions are outlined for the protection of the structure and at the same time of the image and usability of the Aqueduct.
\end{abstract}




\section{INTRODUCTION}

\subsection{Historical outline}

The Claudius Aqueduct (Caligola, 37-41 AD, Claudio, 41-54 AD) has been operating since 47 AD. C. It crosses the hills and the plain of the Roman countryside, with an artificial route 45 miles long (over $66 \mathrm{~km}$ ) which joins the natural one of the Aniene Valley. The hilly upper section has many examples of hydraulic and structural engineering, which are necessary to divert water through the hills. The lower section - about a quarter of the structure - is instead completely emerging from the countryside plan that becomes almost flat approaching to Rome and the Tiber Valley. From Capannelle towards Rome, the height of the conduit quickly arises from the countryside ground-level, quickly reaching a height around $20 \mathrm{~m}$ above the elevation profile of the soil. The hydraulic canal was kept at a remarkably high altitude over the city to facilitate the subsequent parceling and branching towards buildings and baths. In fact, nowadays in the countryside it constitutes a primary presence for several kilometers, up to the Roman Aurelian Walls (270 - 275), which incorporate the Aqueduct for substantial stretches (fig. 1, left).

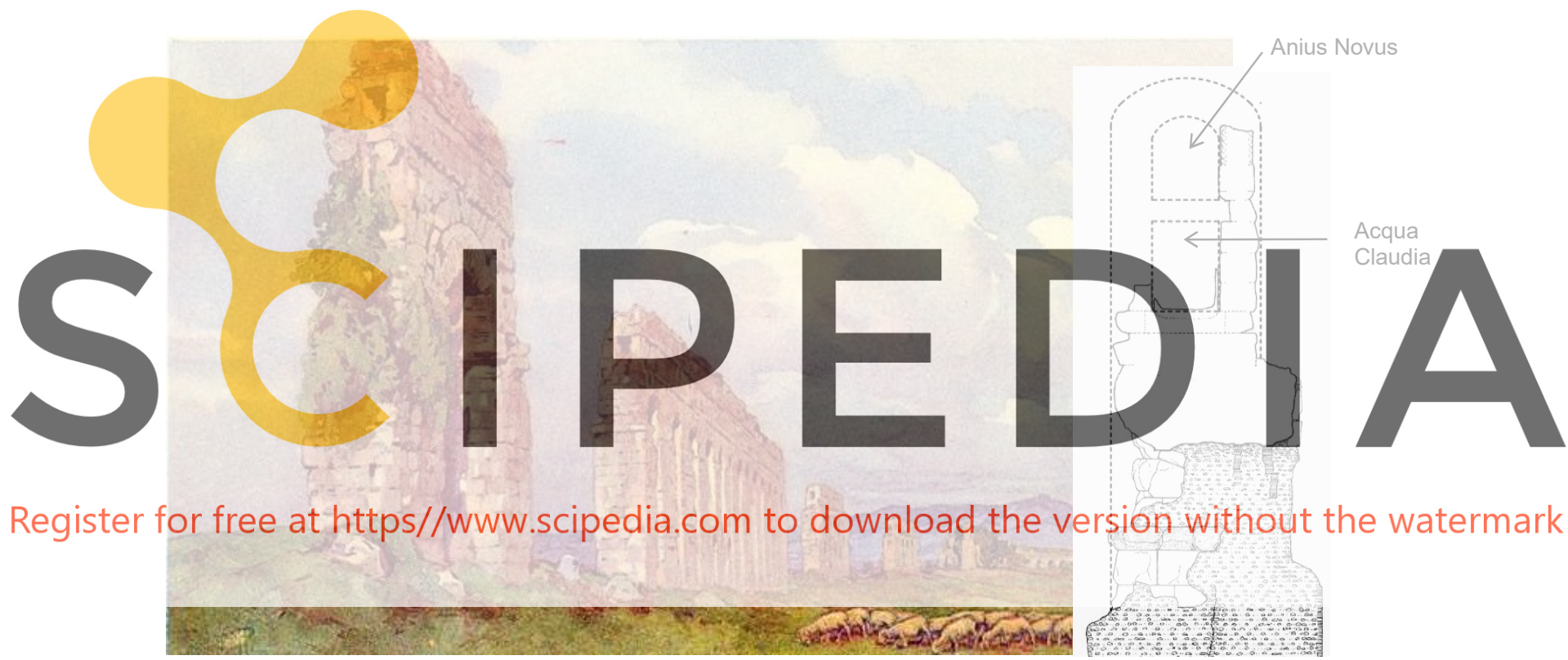

Figure 1: Historical image of the Aqueduct in a late 19th century watercolor. The typical cross section of the upper part of the Aqueduct is re-represented (archway, Claudius and Anius Novus water hydraulic conduit).

The masonries of the Claudio aqueduct were built exclusively in blocks, mostly of peperino, which is a volcanic sedimentary stone. Even though the architectural design of the arches has a rational rhythm, the size and quality of the blocks is completely heterogeneous in shape, size and quality. Modification, consolidation and reinforcement works already started in the 1st century. The constructive phases of the structure are characterized by the almost immediate overlap of the Anius Novus conduct. The use of the existing supporting structure for a double channeling follows other previous examples, but the Anius Novus is made of rubble masonry with sides in opus mixtum and is conserved only in minimal residual portions (fig. 1, right).

However, the second hydraulic line does not appear to be the cause of the reinforcement works. In fact, these works were carried out in sections and entailed huge funding already in 71 and 81 . After that, the consolidations continued in the 2nd century, during Hadrian and Severian Ages, with the 
reinforcement of other segments made with well executed opus testaceum and in 4th century the works were continued with the characteristic inhomogeneity of building materials. The maintenance continued until the 10th century when the structure was substantially abandoned. Subsequently, the construction was also systematically attacked to obtain material with a consequent strong reduction in discontinuous sections. Especially for the construction of the Felice Aqueduct in 16th century, which runs parallel to the Claudius aqueduct ${ }^{[1,2,5,6]}$.

\subsection{Context and purpose of the study}

The starting point for this study was a consultation requested by the Archaeological Superintendence. Emergency intervention was needed for a portion of the Aqueduct located in the Appia Antica park near Capannelle. In this section, problems occurred both for the safety of the population and for the loss of original materials. ${ }^{1}$ The works were aimed at the direct elimination of structural problems by avoiding the incipient collapse of unstable portions as the supports for fractured roof lintels and the local repair of unstable parts. Work has also been planned to mitigate the conditions that accelerate the degradation of materials, such as infiltrations and aggressive vegetation that would have caused new and serious damage to the structures.
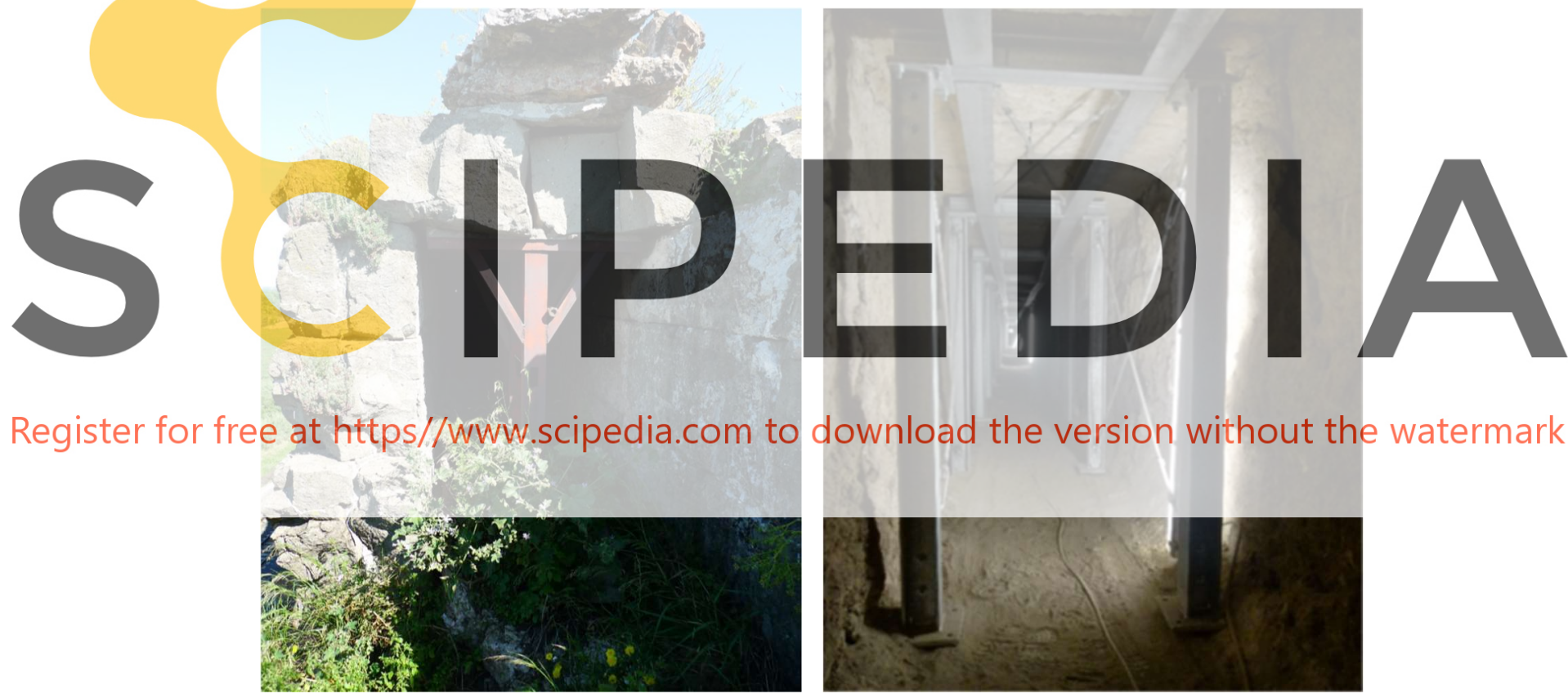

Register for free at https//www.scipedia.com to

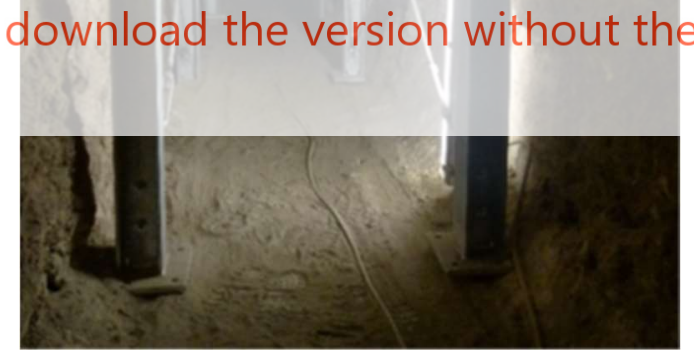

Figure 2: View of the hydraulic conduit in the end part of this section of the Claudius Aqueduct. The broken lintel is prop up by a metal support and in the upper part there is a residue of the Anius Novus upper structure. On the left, a recent anti-seismic intervention on an adjacent section.

During the consultancy, some particular aspects were investigated, concerning the conduit and the relative lytic covering architraves. These investigations did not lead to direct operational conclusions.

\footnotetext{
${ }^{1}$ The restoration was guided by Arch. Giacomo Restante (W.D.), by Arch. Stefano Antonetti (P.M.) and by Dr. Antonella Bonini (archaeologist) and performed by DucaleRestauro S.r.l. from Venice (specialized company). Thanks to Prof. Cesare Tocci (Politecnico di Torino) for adding value to this project through his inspiring suggestions and his great availability.
} 
Indeed, the funding just covered the disposing of temporary interventions, but we hope that our studies will be useful for a future conservative maintenance works.

The attention has been focused on the critical conditions of the duct related to the state of the lytic roof lintels that have many fractures. On this occasion, the cracks of the arches corresponding to the pillars from 1st to 31 st were documented and shoring-up devices present were also reported.

The different elements of deterioration can hardly be interpreted in a sufficiently simple systematic framework that adequately reflects the overall behavior of the structure.

The vibrations induced by the earthquakes that occurred in the two millennia of existence of the monument or the settlements of the grounds and walls have caused damage. However, the respective influence of the numerous parameters interfering in the behavior of the monument can hardly be defined. The most important parameters are: heights of springer of the ducts covering, which are different from in every part; the lack of homogeneity of the material and the degradation; the conditions of the soil; the structural responses, altered locally by the degradation.

The study aimed rather to identify possible methods of intervention on the stone roofs of the hydraulic conduits, using a symptomatic treatment logic. Starting from the critical conditions of the building, the negative effects brought about by degradation and discontinuities were identified to locally mitigate the consequences and to improve the original reactive capacities of the monument. This section's degradation conditions reflect those generally found in other surviving portions of the ancient infrastructure and the considerations carried out - exceeding the specific features of the section under investigation - can also be considered extensible to other portions of the Aqueduct.
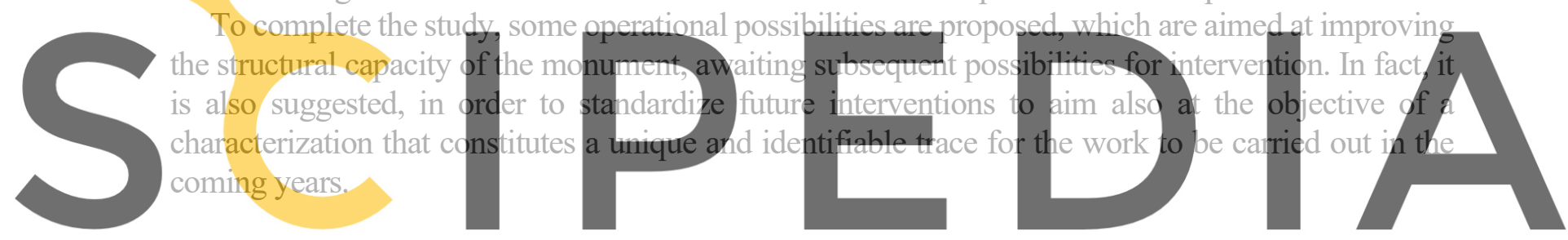

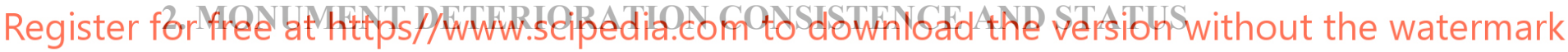

From the consistency point of view, the hydraulic conduit can be described as a tunnel with two vertical and parallel walls made of stone blocks laid in semi-horizontal layers, sumounted by a lithic plate formed by lintels made up of squared, irregular blocks, placed side by side. On both sides of the lintels there are small protrusions on external facing, as a continuous frame that defines the front. Stone elements of this frame are not always whole; probably in most cases, on one or both ends, the portions that make up the projection of the architraves that cover the span and rest only on a part of the thickness of the longitudinal partitions have been added.

Almost all the wall elements were made with uneven quality peperino. To build the horizontal lintels were chosen materials of greater consistency, well cemented; whereas in the vertical masonries there are also blocks obtained from less cohesive peppers, tending to degrade with greater ease. All the elements that make up the two walls show signs of erosion on externals sides caused by atmospheric agents and stresses. These masonries were initially prepared with a sort of anathyrosis (i.e. with the well-worked ashlars on the edges and with a less finish accurate on the central surface of the face in view), currently have edges often worn, sometimes chipped. A less advanced deterioration is observed on the more protected internal face. The elements that make up the section of the duct are affected by cracking phenomena characterized essentially by a pseudo-longitudinal 
orientation of the water conduit and the roof lintels. The longitudinal discontinuities of the arches are visible from the outside from below, while inside they are often hidden by the stratification of the limestone collected at the base of the duct, but are revealed by the detachment of the horizontal layer of limestone and the original screed related to the internal facing of the walls, due to the relative location.
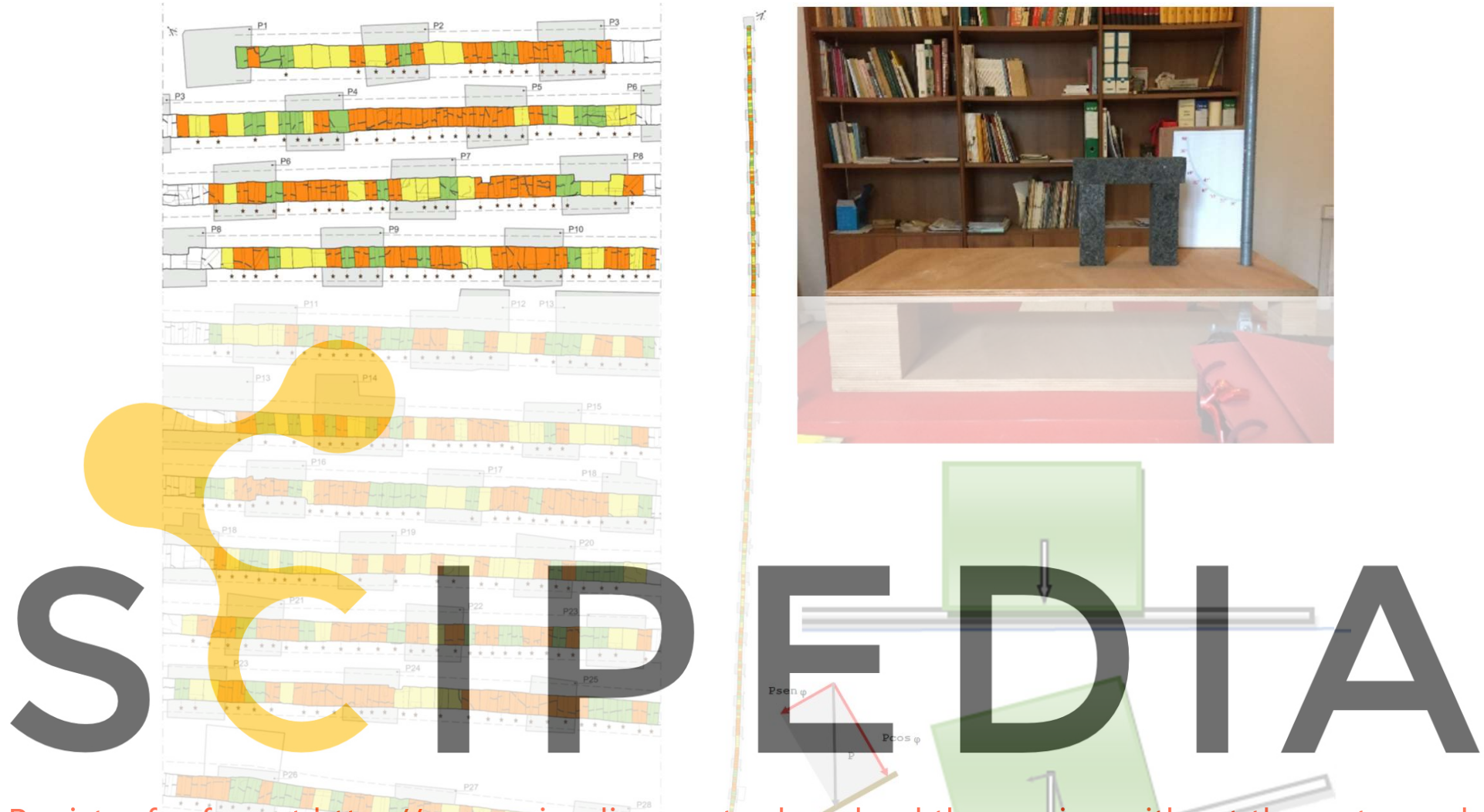

Register for free at https//www.scipedia.com to
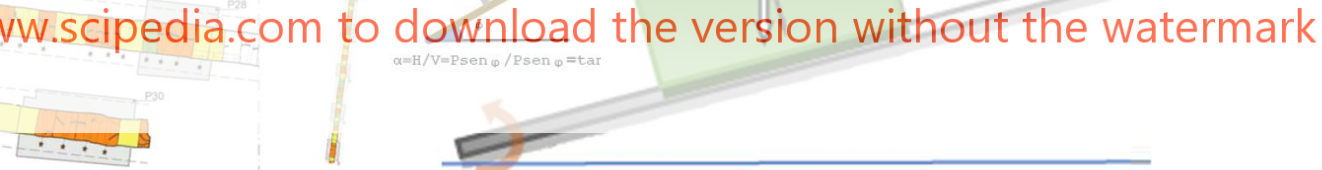

Figure 3: Survey of the state of cracking degradation in the different sections of the portion of Aqueduct analyzed, edited by Arch. P. Agrimi and re-elaborate by the author (left); inclinable plane used in the experimentation (kindly provided by DucaleRestauro S.r.l.) with the scheme adopted (right).

On this occasion, taking advantage of the special condition of accessibility to the tunnel, the survey focused above all on the cracked condition of the ceiling, considered the most critical issue. The mapping of the cracking of the lithic elements covering the roof have been extended to the entire section - arches from 1st to 31st), also localizing the presence of the support devices already adopted or introduced on this occasion. In addition, was detected the final section, where it is possible to appreciate the thicknesses of the elements constituting the span.

The fractures of the lintels caused structural failures with relative displacements due to the reduction of the continuity constraint and to the assumption of a different equilibrium condition, often characterized by relative sliding and lower degrees of safety. The effects of these stability adjustments 
have induced the justified apprehension that recommended the immediate insertion of the internal support props to avoid the feared collapse of the lintels, taking advantage on the unused tunnel and its poor visibility from outside (fig. 2).

These supports are temporary and replicate a type of device already used in the last century, which is made of vertical metal supports, T-shaped with wooden planks that mediate the contrast of the architraves towards the intrados and under the support of the central upright on cocciopesto of the duct or on secular sediments limestone.

As can be seen in fig. 3, the fracturing of the lintels is widespread, but not homogeneous. Some elements appear intact (yellow) and others interrupted by the discontinuity that is sometimes positioned in the center (green) and often near one of the edges (orange). The presence of multiple fractures is rarely observed and sporadic is the case of an actual partial collapse; this temporary balance has recommended and allowed, in the past and at present, the insertion of the metallic supports to prevent a progression of deformation phenomena and possible collapses.

\section{DEFINITION OF THE STUDY MODEL}

The models studied have been defined based on the survey, with the approximations necessary to make the section as representative as possible. Only transverse vulnerability is considered, assuming as certain an adequate capacity in the longitudinal direction.

The side walls show critical issues related to aging and the lack of homogeneity of the material, which appear more relevant outside where the masonries are not protected by coatings and by the condition of a closed environment. To consider this generaized reduction of the resistant section, a retraction of the hinges

On the other hand, passing through the who by the remains of the Ani of the duct. The fractures that cross the thickness of

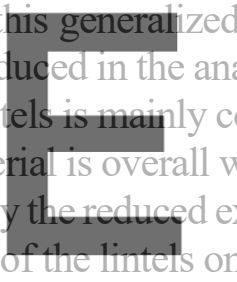
reduction of the resista
constituted by fractures that preserved because it
well A the most incident element of static degradation. The roof of the hydraulic conduit can be assimilated

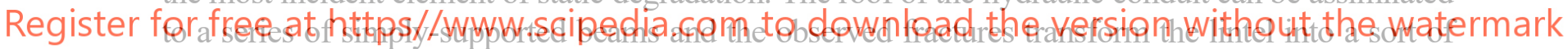

natural straight arch, which is supported as an arch set on the side walls and with mounts almost equal to the thickness itselif.

In summary: some lintels have preserved monolithic shapes, but largely show fractures passing through the entire thickness, with regular orientation or levels with different configurations. The scheme in fig. 5 shows fractures represented simultaneously but, in general, only one is present on the same element and the scheme must also be considered in the symmetrical version. The lesions are of type A, B, or C: in case B, a portion of the lintel takes on a larger size than the other - the center of gravity is within the gap between the walls), and normally give in $\mathrm{D}$ before finding an adequate contrast in the natural arch. Type $\mathrm{C}$ is the fracture with the greatest risks due to the very reduced support section and because the lesion is not visible. Therefore, the possible presence of these discontinuities is not appreciable in the performed survey, but it is only hypothesized during the study comparing other portions of the Aqueduct. The T cuts are sometimes original, but are not always present and symmetrical on both ends of the same slab; it is possible to observe them only in the sections in which the building has lost its continuity and, consequently, they do not appear in the survey carried out as they cannot be identified.

Overall, there is a rather varied set of situations that has forced us to consider different schemes to 
represent the current state of the structure, made uneven by the different degradation conditions induced by the fractures. A basic scheme was taken from the longitudinal section, which is traced back to a typical section (fig. 5, above left). On this scheme different models of structural behavior have been hypothesized. In fact, two types of structural problems are highlighted by examining the conditions of the water conduit: the first one is related to the stability of the lintels fractured in ordinary conditions and the second depends on the ability of the structure to resist seismic stresses.

In the first case, vertical supports have been introduced, to ensure the stability of the architraves subject to their weight and to that of the masses above. In the second case, only recently, in another section of the Aqueduct, have been inserted frame devices which are, however, particularly invasive, even if not visible from the outside (fig. 1. right).

In a broader analysis, other critical issues presented by the Aqueduct structure must be taken into consideration, such as the tendency to longitudinal segregation of the arches with divergence into two portions, the general deterioration of the pylons, the unevenness of the state of degradation of the blocks, etc.

These types of deterioration are already studied in other previous interventions ${ }^{[4]}$ and there are forthcoming contributions. Within the limits of this analysis, only the portion of the hydraulic conduit was considered; downstream of the local checks, the specific conditions influenced by the tax quota were considered, variable in relation to the elevation of the soil, since the level of the duct set at an almost constant altitude. In order to simplify, other specific conditions, varying from section to section, have not been considered. For example, the portions related to the remains of the above structures of the Anius Novus.

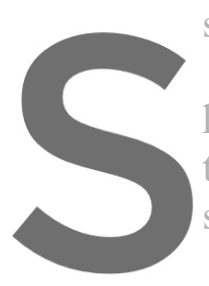

\section{The following figures} kinematic mechanisms the absence of sliding, p sliding between bodies 3 and 4 .
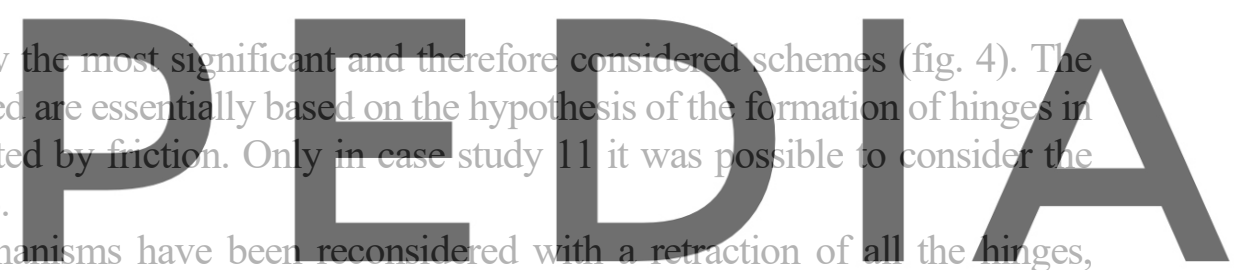

activated simulating both the classic local subsidence on the axis of the hinge and the general state of

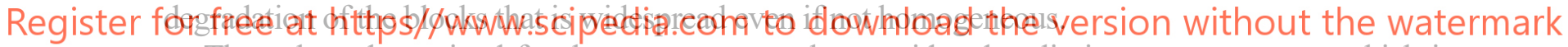

The values determined for the two cases can be considered as limits: an upper one - which is difficult to consider as a realistic result - and a lower one, more useful because it is precautionary, but sometimes more congruent with the state of degradation of the blocks.

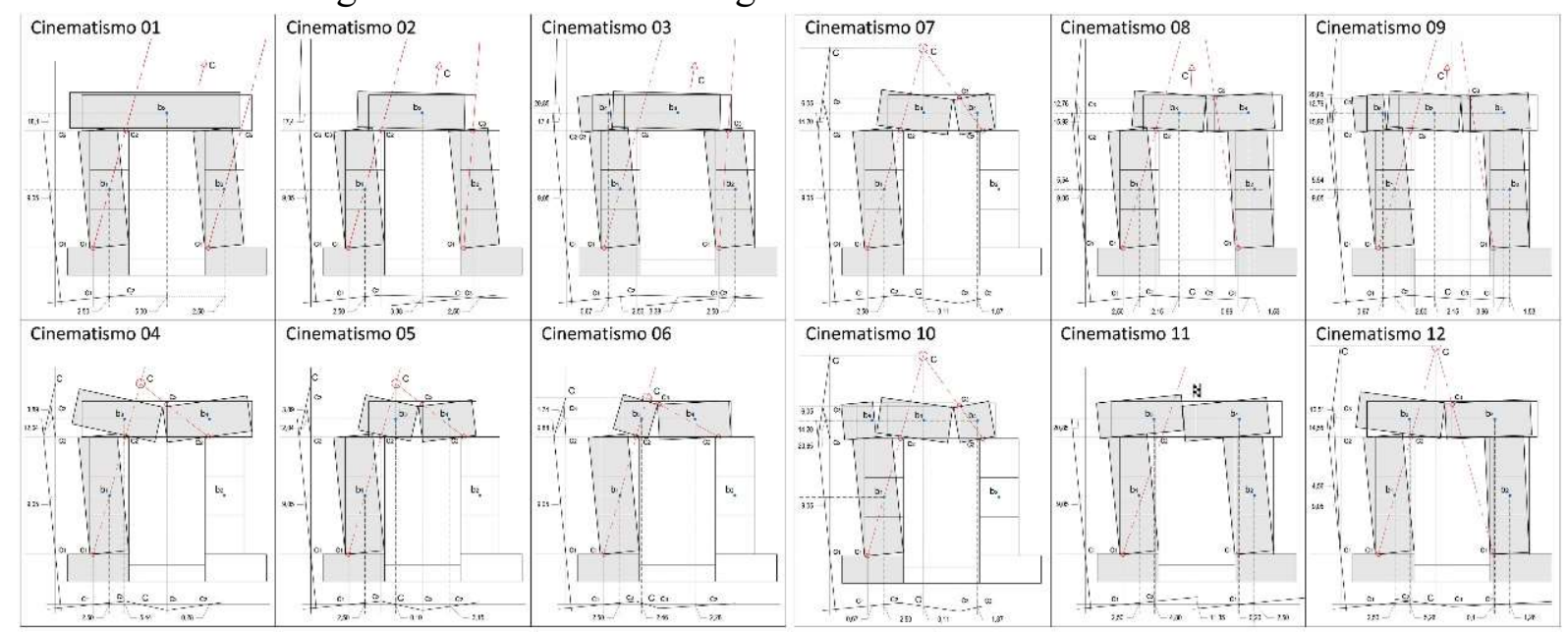

Figure 4: Synoptic framework of the kinematic mechanisms examined. 
According to the studies performed during Nineties by Antonino Giuffrè and Vittorio Ceradini ${ }^{[3]}$, the work on these models was conducted with kinematic and empirical analysis. So, it was possible to make an immediate comparison with a real modeling in 1:10 scale, with elements of $5 \mathrm{~cm}$ thick, corresponding to $50 \mathrm{~cm}$. The models were subjected to static stresses, equivalent to the seismic stress condition, simulated by rotating the support surface of the models. That determines an inclination of the system whereby the vertical weight can ideally be broken down into two components similar to those induced - in real conditions - simultaneously by gravity and seismic actions (one normal to the plane and one parallel to it). The relationship between the two components is like that between the force of gravity and the seismic thrust (fig. 3, right).

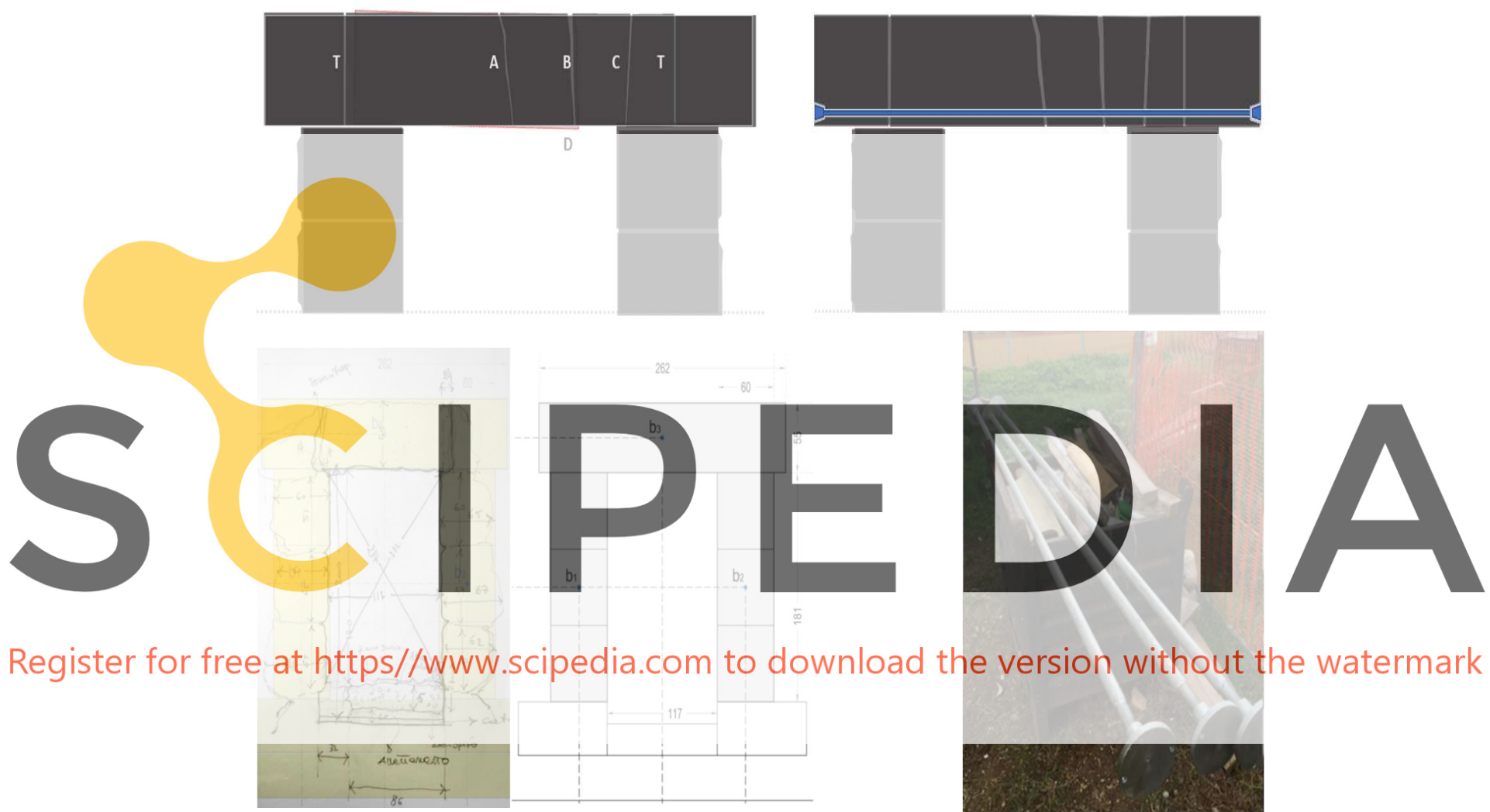

Figure 5: Representative scheme of the lintel and of the typologically repeated fractures (above, left); indication for the tie bars location (above, right); the survey and the used scheme (bottom, left); the tie bars proposed and already used in other sections of the aqueduct (right).

\section{RESULTS OF THE KINEMATIC STUDY AND OF THE EXPERIMENTATION}

The results of the graphical-numerical modeling and of the direct experimentation have been summarized in the following tables.

Figure 6 reports some of the results obtained with the study of the mechanisms in terms of load multiplier necessary for the activation of the mechanism; the values are obtained considering the activated hinges set back by $5 \mathrm{~cm}$ to give a general account of both the effects of the load concentrations and the degradation of the material. In the study, the homologous values were also calculated considering intact hinges, but for brevity they were not reported. 
Figure 7 lists the results obtained empirically in the different cases already examined with numerical analysis. The photographs show the mechanism that occurred in the experiment.

All the data obtained for a possible comparison have been reported in Figure 8. Moreover, the data in terms of acceleration - calculated according to the Italian standard - have been added, with a different level of knowledge and relative $\mathrm{Fc}$, at different altitudes in correspondence with the altimetry of the different ground levels crossed by the aqueduct. In many cases the mechanism is implemented in the theoretically foreseen manner; sometimes there is a discrepancy with respect to the starting hypotheses which highlights the possibility of sliding which, as mentioned, have not been taken into consideration in the numerical analysis - with the exception of case 11.

Generally, the results in terms of multiplier - determined in relation to the inclination reached at the time of priming - follow the numerical forecasts, however assuming a magnitude between the two limit values, with intact or backward hinges.

Study case 4 does not have a corresponding application. The mechanism that actually occurs is the same considered successively as case 11: the central hinge does not be formed because the sliding occurs between the two segments, which remain integral to the respective abutments and the projection of the center of gravity does not come out from the support of the slab. This process does not produce a natural arch effect by anticipating the activation of the kinematic chain. In the case study 11, the activation occurs with a multiplier equivalent to the one determined without considering the gripping work, as if the force exchanged by the two parts that remain united does not actually exchange at the time of the activation. The two portions - abutment and straight arch - separately tested, have two different multipliers (upper left, and lower right). They can be activated to gether with a multiplier that averages Also in study cases by horizontal sliding of the of the major block of linte a slightly higher thrust than expected; subsequently arch takes on an even lower mount and therefore contributes to the early activation of the mechanism. the wall, which, however, initially caves in, but then - at the end of the thrust in correspondence with the collapse of the horizontal block - maintains the position reached.

In case 12 an artifice was attempted to verify the response of the whole structure if the sliding had been delayed. Thanks to the sliding preventing of the sections in contact in the centerline, a mechanism similar to case 4 occurs. This mechanism brings back values of greater capacity even if not comparable with those the mechanism initially provided, but are not feasible

Generally, there is a discreet natural capacity of the original hydraulic conduit which, however, decreases with the fracturing of the roofing slab. This justifies the persistence of the structure over time. However, the lintels today appear fractured probably for causes not related to seismic stresses. In most cases, the stability situation with ordinary conditions do not cause collapse of the coverage. The necessity to find more stable configurations - especially where the fracture is close to the supports - produces those small slips deeply observed. The structures vulnerability towards the seismic event is quite evident in case of partial losses and fractured elements. It follows the requirement to intervene especially in the case of fractures that are not central and when the phenomenon affects contiguous lintels. 


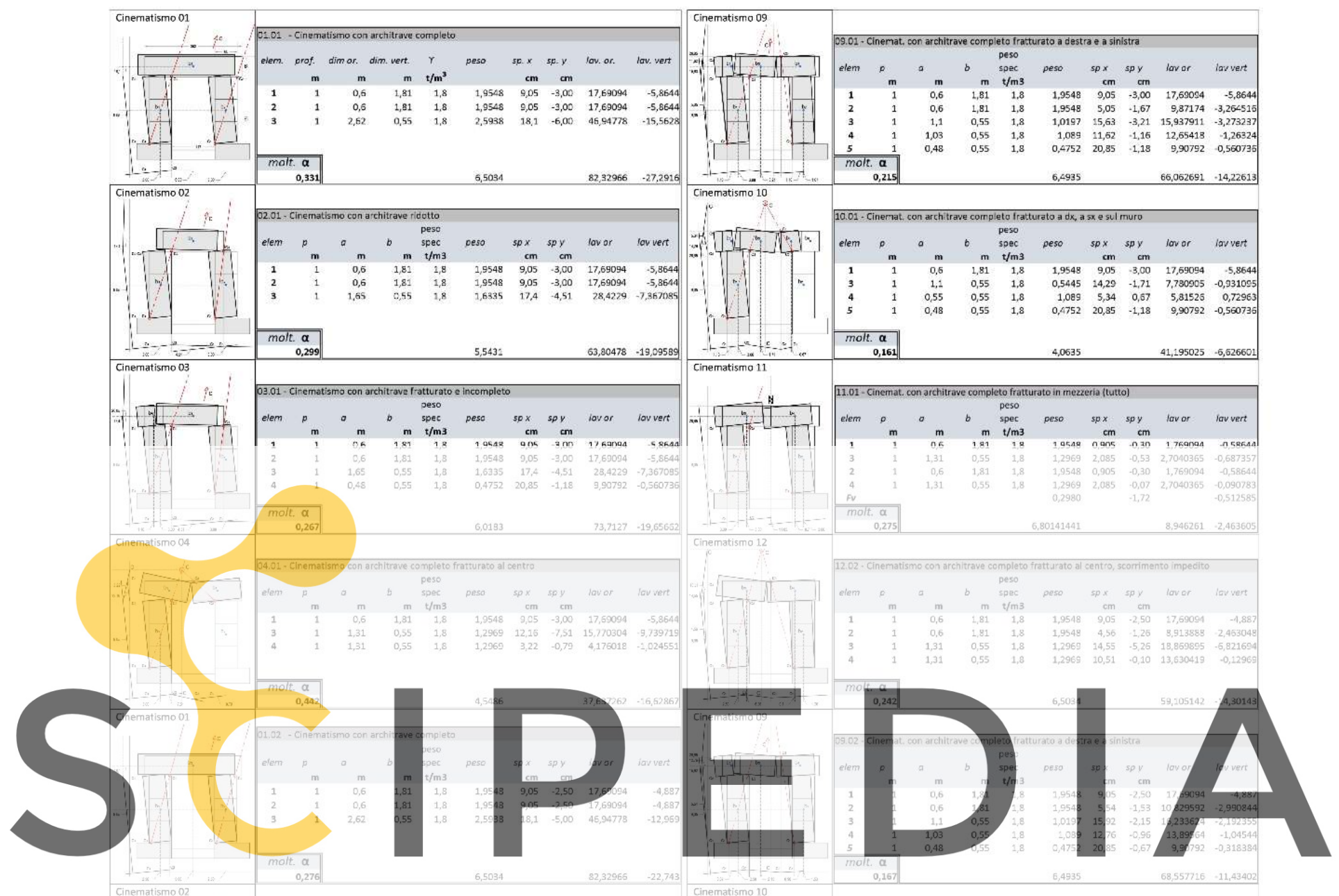

Register for free at https//www.scipedia.com to download the version without the watermark

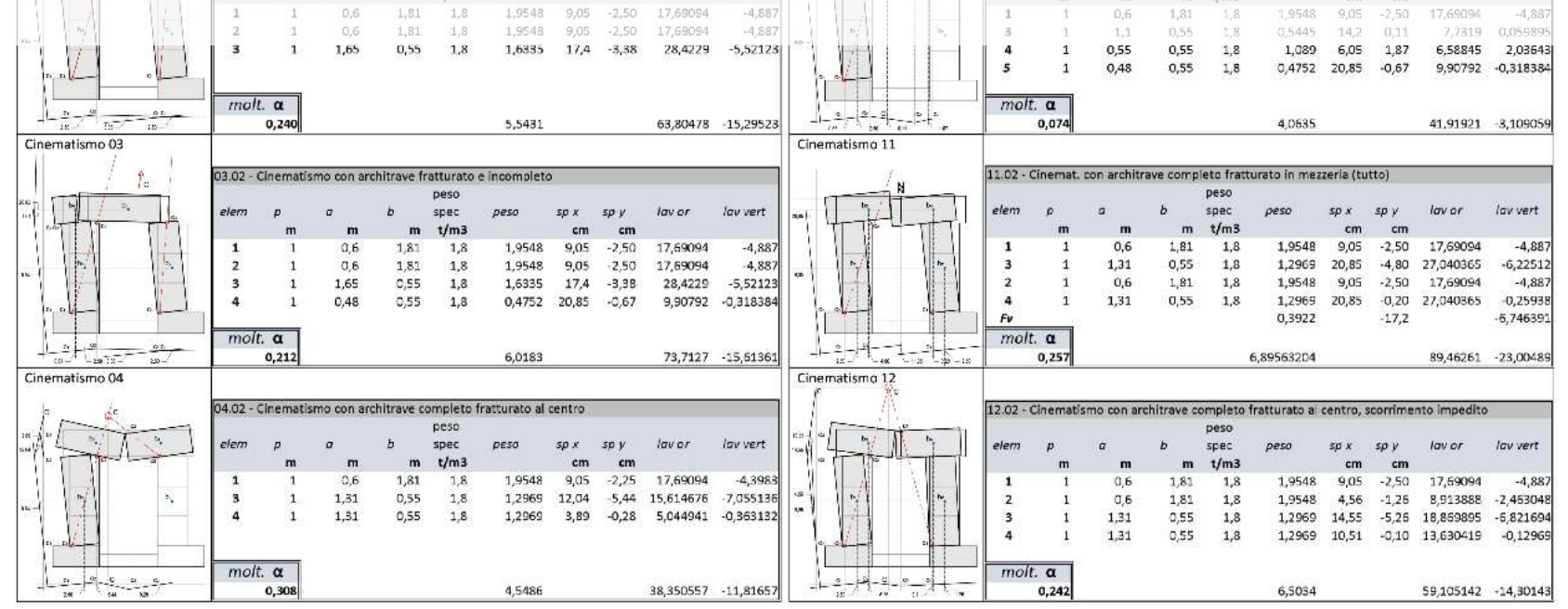

Figure 6: Summary of the expected results with activated retracted hinges. 


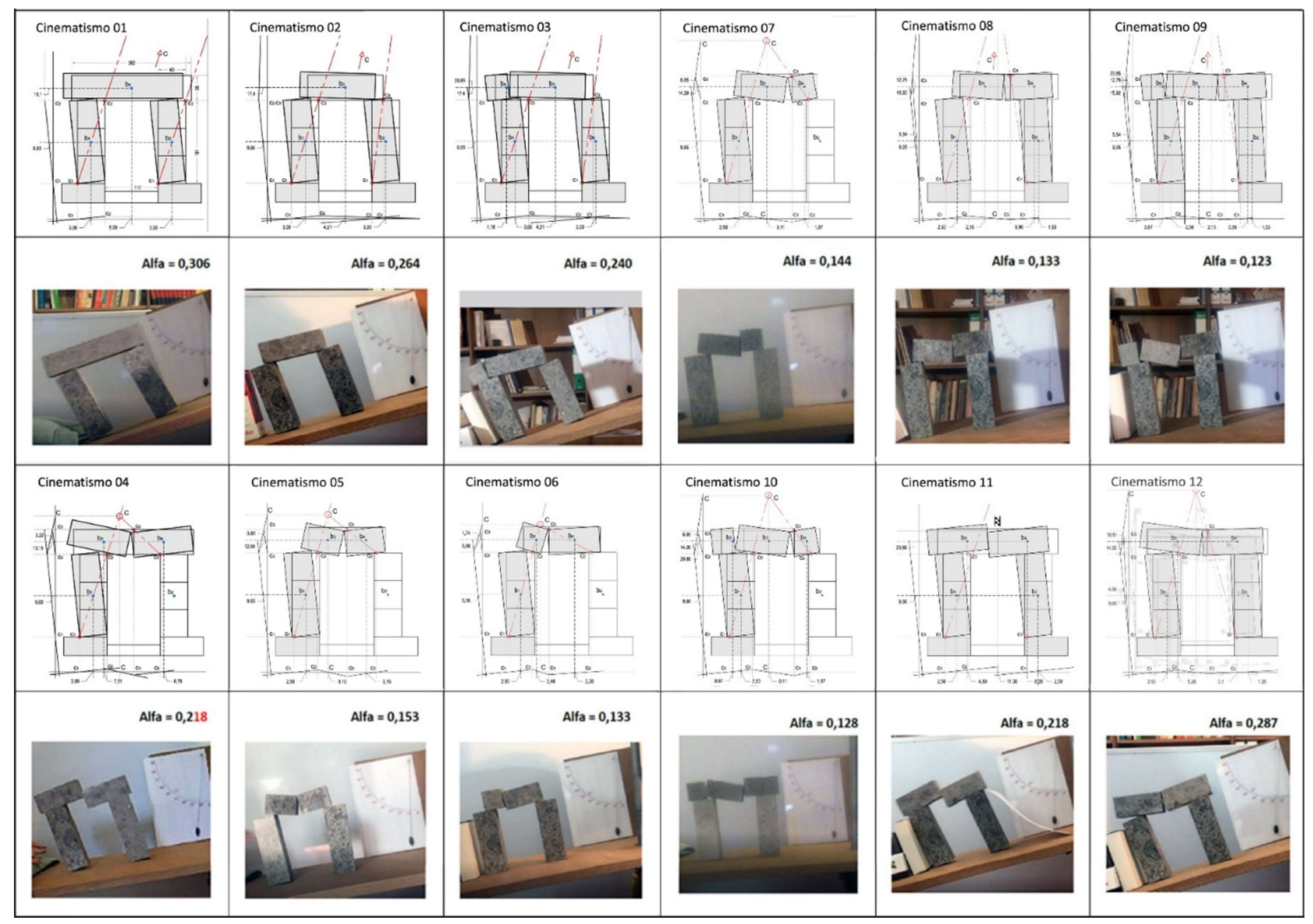

Figure 7: Synthesis of experimental results with physical model.

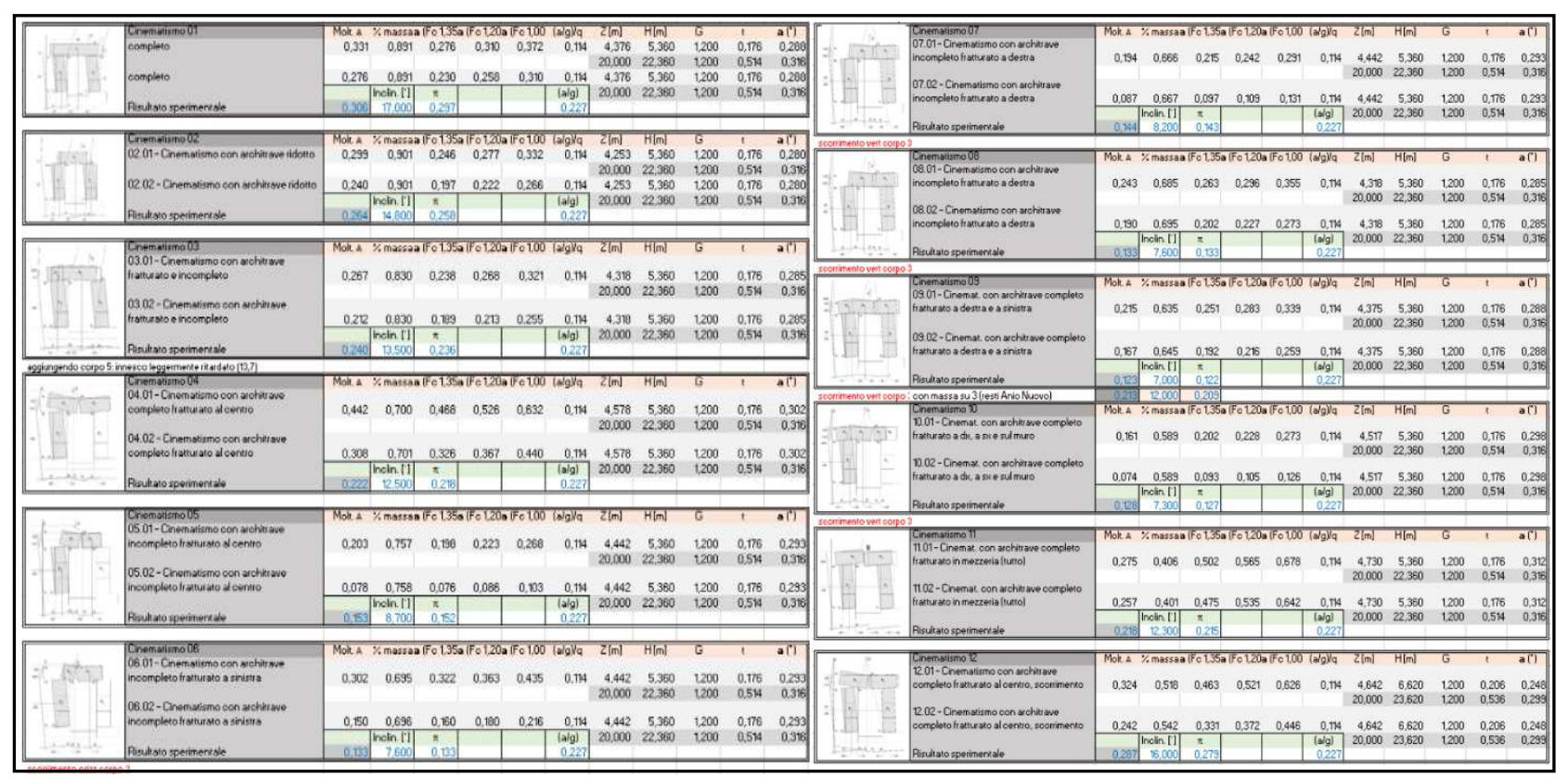

Figure 8: Summary and comparison of the results obtained with the kinematic analyzes and with the direct experimentation, related to the seismic accelerations of collapse assessed according to the Italian legislation. 


\section{CONCLUSIONS ON THE PRACTICAL ASPECTS OF THE INTERVENTION}

In conclusion, to obtain an improvement in capacity, can be inserted devices capable of supporting the roofing slab tracing the architrave back to its original monolithic nature. The measure can be implemented by inserting titanium bars - or stainless steel - which should exert a modest compressive force, sufficient to avoid rotations and also vertical translations in the fractured sections (fig. 5, above right). The failure due to shear force near the supports is, in fact, one of the most penalizing consequences of the structural deterioration for the wood. The proposed intervention could be a substitute for the internal supports and allow full suitability of the duct. The insertion of titanium bars would not be burdensome for the lithic material as it requires the execution of small diameter holes, which can be made without difficulties. This intervention certainly appears suggestive since it allows to find a structural stability close to the original one, because it doesn't introduce invasive elements in the cavity.

The safety margin would probably be lower than those obtainable with the insertion of metal frames (fig. 2, right). However, the intervention would result minimal formal and functional invasiveness, not obstructing visibility and accessibility of the conduit. The bar - constituting a sort of tie rod - would allow the arched behavior with limited thrust of the lintel, whether it is intact (precautionary intent) or fractured (improvement intent). The presence of intact lintels allows a containing effect, even on fractured ones, provided that the latter are suitably interspersed with healthy ones. Consideration that introduces various intervention management possibilities by grading the number of bars to be inserted. End-plate anchors, as already verified in previous interventions, can easily be disguised. Once inserted, the bar can be activated with forcing, producing an axial force of minimum intensity. The same force can be transferred to the lithic straight arch by anchoring with mortar or resin injection; otherwise it can be possible to operate with dry techniques to obtain maximum reversibility. The bar can be activated by forcing the small end-plate anchors, one of which is fixed and the other can be screwed using a threaded sleeve.

\section{REFERENCES}

[1] Arizza, M. and Santolini Giordani, R. L'acquedotto Claudio: restauri antichi e moderni. In: S. Francocci (Ed.): Materiali e Tecniche. Esperienze di restauro a confronto, Conference proceedings (Nepi, novembre 29 ${ }^{\text {th }} 2008$ ), Davide Ghaleb Editore (2011), pp. 11-15.

[2] Ashby, T. Gli acquedotti dell'antica Roma. Trasl. by A. Aiosa Gambardella [Ashby, T. The Aqueducts of Ancient Rome. Richmond I. A. (Ed.), Clarendon Press (1935)], Quasar (1991).

[3] Ceradini, V. Indagini sperimentali su modelli di opera muraria. In: A. Giuffrè (Ed.): Sicurezza e Conservazione dei centri storici - Il caso Ortigia, Editori Laterza (1993).

[4] De Cesaris F. and Vergantini L. Acquedotto Claudio: interventi di rinforzo statico e di restauro di alcune arcate nel Parco degli Acquedotti. In: S. Francocci (Ed.): Materiali e Tecniche. Esperienze di restauro a confronto, Conference proceedings (Nepi, novembre $29^{\text {th }}, 2008$ ), Davide Ghaleb Editore (2011), pp. 16-31.

[5] Orsini, B. Comentario di Sesto Giulio Frontino degli acquedotti della citta' di Roma con note e figure illustrato da Baldassarre Orsini professore delle belle arti e direttore dell'accademia del disegno di Perugia, Stamperia camerale di Carlo Baduel (1805).

[6] van Deman, E. B. The building of the Roman aqueducts. McGrath Pub. (1973; reprinted in its original form by Carnegie Institution 1934). 